\title{
Multilayer Graphene Encapsulation on the Fe Nanoparticles Starting from Fe Chloride Precursors
}

\author{
Sıddıka Mertdinç ${ }^{1}$, M. Lütfi Öveçoğlu ${ }^{1}$, Duygu Ağaoğulları ${ }^{1}$ \\ ${ }^{1}$ Istanbul Technical University, Chemical and Metallurgical Engineering Faculty, Metallurgical and Materials Engineering \\ Department, Graphene \& 2D Materials Laboratory, 34469, Istanbul, Turkey \\ mertdinc@itu.edu.tr; ovecoglu@itu.edu.tr; bozkurtdu@itu.edu.tr
}

\section{Extended Abstract}

The interest of the magnetic nanoparticles has increased due to their various application fields [1,2]. Magnetic iron nanoparticles were used as drug or gene delivery agents at cancer treatments like hyperthermia, diseases detections and imaging studies such as magnetic resonance imaging [1,3,4]. Not only biomedical applications, but also iron based magnetic nanoparticles are desired materials for catalytic applications, waste water treatment and electronic utilizations (supercapacitors, batteries etc.) [1]. Magnetic nanoparticles must be resisted to oxidation and high temperatures for various engineering applications. Therefore, chemically stable layers are coated on ferromagnetic nanoparticles (Fe, Ni, Co etc.) [5]. Graphene encapsulation protects the magnetic core materials against corrosion and also increases the surface area and reduce the agglomerations of the particles [3,5]. Solvothermal method, sol-gel method, combustion synthesis, plasma, electrophoretic deposition method and chemical vapor deposition (CVD) method are used to synthesize graphene coated nanoparticles [6,7]. Amongst them, CVD method is a widely studied method [3,7].

In this study, graphene encapsulation studies were performed using CVD system that consisted of tube furnace, vacuum pump and gas flowmeters. Thus, synthesis optimizations of the graphene encapsulated Fe nanoparticles were conducted by changing CVD temperature and dwelling time of the system.

First, iron chloride $\left(\mathrm{FeCl}_{3} \cdot 6 \mathrm{H}_{2} \mathrm{O}\right)$ salts were mixed with fumed silica in ethanol and heated until the ethanol was vaporized to prepare precursor powders for chemical vapor deposition (CVD). These prepared precursor powders were placed into the three different quartz boats and they located at the heating zone of the furnace. CVD system was fed with hydrogen $\left(\mathrm{H}_{2}\right)$ and methane $\left(\mathrm{CH}_{4}\right)$ gas flows with constant flow rates $\left(100 \mathrm{ml} / \mathrm{min} \mathrm{H}_{2}\right.$ and $\left.100 \mathrm{ml} / \mathrm{min} \mathrm{CH}_{4}\right)$ for both reduction of $\mathrm{FeCl}_{3} \cdot 6 \mathrm{H}_{2} \mathrm{O}$ to $\mathrm{Fe}$ and $\mathrm{CH}_{4}$ decomposition. The furnace heated up to 900 and $950^{\circ} \mathrm{C}$ under $\mathrm{H}_{2} / \mathrm{CH}_{4}$ gas flows. Besides, dwelling time varied between 45 to $90 \mathrm{~min}$. Vacuum gauge was fixed to $30 \mathrm{mbar}$. All synthesized powders were purified with 2 M HF to remove the silica powders. Subsequently, uncoated Fe particles leached out using $4 \mathrm{M} \mathrm{HCl}$ acid solution.

$\mathrm{X}$-Ray diffractometer was used for phase identifications before and after leaching steps. Reduction of $\mathrm{FeCl}_{3} \cdot 6 \mathrm{H}_{2} \mathrm{O}$ to $\mathrm{Fe}$, carbon formation and removing of the silica were investigated via XRD patterns. Also, Raman spectrum was used for identifications of the graphene multilayers. Microstructural characterizations of powders were conducted using scanning electron microscope (SEM) and transmission electron microscope (TEM) equipped with energy dispersive spectroscopy (EDS). Core-shell structures of the synthesized particles were clearly identified from the TEM images. Additionally, magnetic properties of the synthesized and purified powders were determined using vibrating sample magnetometer (VSM). According to the hysteresis loops, synthesized powders have soft magnetic properties with saturation magnetisation (between 95.60 and $134.69 \mathrm{emu} / \mathrm{g}$ ) and coercivity (between 242.04 and $344.51 \mathrm{Oe}$ ) values.

\section{References}

[1] L. Cervera, J.I. Peréz-Landazábal, E. Garaio, M. Monteserín, S. Larumbe, F. Martín, C. Gómez-Polo, Fe-C nanoparticles obtained from thermal decomposition employing sugars as reducing agents, Journal of Alloys and Compounds, 2021, vol. 863, 158065.

[2] M.R. Sanaee, E. Bertran, Synthesis of Carbon Encapsulated Mono- and Multi-Iron Nanoparticles, Journal of Nanomaterials, 2015.

[3] D. Ağaoğulları, S.J. Madsen, B. Ögüt, A.L. Koh, R. Sinclair, Synthesis and characterization of graphite-encapsulated iron nanoparticles from ball milling-assisted low-pressure chemical vapor deposition, Carbon, 2017, vol. 124, pp. 
$170-179$.

[4] F.R. Li, W.H. Yan, Y.H. Guo, H. Qi, H.X. Zhou, Preparation of carboplatin-Fe@C-loaded chitosan nanoparticles and study on hyperthermia combined with pharmacotherapy for liver cancer, International Journal of Hyperthermia, 2009, vol. 25, pp. 383-391.

[5] M. Bystrzejewski, S. Cudziło, A. Huczko, H. Lange, G. Soucy, G. Cota-Sanchez, W. Kaszuwara, Carbon encapsulated magnetic nanoparticles for biomedical applications: Thermal stability studies, Biomolecular Engineering, 2007, vol. 24, pp.555-558.

[6] J. Liao, Y. Li, Z. Wang, L. Lv, L. Chang, In-situ preparation of Fe3O4/graphene nanocomposites and their electrochemical performances for supercapacitor, Materials Chemistry and Physics, 2021, vol.. 258, 123995.

[7] D. Kuang, L. Hou, S. Wang, H. Luo, L. Deng, J. He, M. Song, Facile synthesis of Fe/Fe3C-C core-shell nanoparticles as a high-efficiency microwave absorber, Applied Surface Science, 2019, vol. 493, pp. 1083-1089.. 